\title{
Pelatihan Keseimbangan dengan Penerapan Yoga pada Lansia dengan Risiko Jatuh di Panti Sosial Tresna Werdha Sabai Nan Aluih Sicincin
}

\author{
Gusti Sumarsih, Fitra Yeni, Arif Rohman Mansur, dan Siti Annisa Irdhani \\ Fakultas Keperawatan, Universitas Andalas, Kampus Limau Manis, Padang, 25163. Indonesia \\ E-mail: gustisumarsih@nrs.unand.ac.id
}

Keywords:

balance nutrition,

immunity,

nutrition

education, student

Kata Kunci:

pelatihan

keseimbangan,

Yoga, lansia,

risiko jatuh

\begin{abstract}
Physical health problems that often occur in the elderly people, for instance falling down to floor. The physiological changing during the aging process increase the client's risk of falling and having an accident. Most falls occur when moving from a bed, stool, and toilet, when going into or out of the bathroom, tripping over the edge of a carpet or door, slipping on wet surfaces and going downstairs. There are many factors that play a role in the occurrence of falls in the elderly, both intrinsic and extrinsic factors. The problems faced by the partners at this time include, there are 20 elderly people at the Social Home of Tresna Werdha Sabai Nan Aluih Sicincin, experiencing rheumatism, 10 seniors have experienced falls in the last 6 months, 35 elderly people experience urinary incontinence, the elderly do not know to minimize the risk of falling balance in the elderly has not been carried out and has not become a priority at the Social Home. Nursing staff identified cooperative elderly people to be provided with balance training with the application of Yoga. Activities were carried out in accordance with elderly guest houses to implement physical distancing due to pandemic Covid-19. Beside that, we provided leaflets of the Yoga's training, some face masks, snack boxes, and cash for all elderly residents of the Sosial Home.
\end{abstract}
ABSTRAK
Masalah kesehatan fisik yang sering terjadi pada lansia diantaranya yaitu kejadian jatuh pada lansia. Perubahan fisiologis yang terjadi selama proses penuaan meningkatkan risiko klien untuk jatuh dan mengalami kecelakaan. Kejadian jatuh paling sering terjadi saat pindah dari tempat tidur, bangku, dan toilet, ketika hendak masuk atau keluar kamar mandi, tersandung pinggiran karpet atau pintu, terpeleset pada permukaan basah dan turun tangga. Terdapat banyak faktor yang berperan terjadinya jatuh pada lansia baik faktor intrinsik maupun faktori ekstrinsik. Permasalahan yang dihadapi mitra saat ini antara lain: 10 lansia pernah mengalami jatuh 6 bulan terakhir, 35 lansia mengalami inkontenensia urin, lansia tidak tahu cara meminimalkan risiko jatuh, Penyuluhan dan latihan keseimbangan pada lansia belum dilakukan dan belum menjadi prioritas di Panti Sosial Tresna Werdha Sabai Nan Aluih Sicincin. Penyuluh bekerjasama dengan petugas panti untuk mengidentifikasi lansia yang kooperatif untuk diberikan pelatihan keseimbangan dengan penerapan yoga. Kegiatan dilakukan sesuai dengan wisma lansia, sehingga meminimalkan pengumpulan massa dalam jumlah banyak dengan menjaga jarak. Pengabdi juga memberikan leaflet tentang pelatihan keseimbangan dengan penerapan yoga. Pengabdi juga memberikan bantuan berupa masker, snack box, uang saku kepada semua lansia penghuni panti. Luaran dari kegiatan ini adalah peningkatan pemahaman/kesehatan masyarakat, dan publikasi artikel ilmiah. 


\section{PENDAHULUAN}

Penuaan dikaitkan dengan perubahan dalam proses biologis, fisiologis, lingkungan, psikologis, perilaku, dan sosial yang dinamis. Beberapa perubahan terkait usia tidak berbahaya, seperti rambut beruban. Yang lain mengakibatkan penurunan fungsi indera dan aktivitas kehidupan sehari-hari dan peningkatan kerentanan terhadap frekuensi penyakit, kelemahan, atau kecacatan. Padahal, usia lanjut merupakan faktor risiko utama sejumlah penyakit kronis pada manusia (National Institute on Aging, 2021). Dalam waktu hampir lima dekade, persentase lansia Indonesia meningkat sekitar dua kali lipat (1971-2020), yakni menjadi 9,92 persen (26 juta-an) dimana lansia perempuan sekitar satu persen lebih banyak dibandingkan lansia laki-laki (10,43 persen berbanding 9,42 persen). Dari seluruh lansia yang ada di Indonesia, lansia muda (60-69 tahun) jauh mendominasi dengan besaran yang mencapai 64,29 persen, selanjutnya diikuti oleh lansia madya (70-79 tahun) dan lansia tua (80+ tahun) dengan besaran masingmasing 27,23 persen dan 8,49 persen (Badan Pusat Statistik, 2020).

Karena perubahan demografis, populasi dunia semakin menua. Kerusakan fisiologis lansia dapat menyebabkan penurunan kemampuan keseimbangan dan peningkatan risiko jatuh menjadi masalah penting di kalangan lansia. Untuk menangkal penurunan kemampuan keseimbangan, aktivitas fisik telah terbukti efektif (Thomas dkk., 2019). Penuaan mengurangi jumlah air di tendon dan ligamen. Oleh karena itu, tendon dan ligamen menjadi kurang elastis, kaku dan lemah, yang dapat mengurangi mobilitas persendian. Perubahan pada tulang dan sistem sendi menyebabkan penyakit degeneratif yang menyakitkan, osteoartritis dan osteoporosis. Dengan penuaan otot kehilangan kemampuan kontraksi, menjadi kurang elastis dan kehilangan kekuatan (Svraka dkk., 2017).

Kerusakan fisiologis lansia dapat menyebabkan penurunan kemampuan keseimbangan dan peningkatan risiko jatuh menjadi masalah penting di kalangan lansia. Untuk menangkal penurunan kemampuan keseimbangan, aktivitas fisik telah terbukti efektif (Thomas dkk., 2019). Gangguan gaya berjalan dan keseimbangan umum terjadi pada orang dewasa yang lebih tua dan merupakan penyebab utama penurunan populasi ini. Mereka terkait dengan peningkatan morbiditas dan mortalitas, serta penurunan tingkat fungsi. Penyebab umum termasuk artritis dan hipotensi ortostatik; namun, kebanyakan gangguan gaya berjalan dan keseimbangan melibatkan banyak faktor yang berkontribusi. Sebagian besar perubahan gaya berjalan terkait dengan kondisi medis yang mendasari dan tidak boleh dianggap sebagai konsekuensi penuaan yang tak terhindarkan (Salzman, 2010).

Penelitian menunjukkan bahwa keseimbangan yang diubah adalah kolaborator terbesar terhadap jatuh pada lansia dengan korelasi tinggi antara defisit keseimbangan dan kejadian jatuh. Iyengar yoga, salah satu teknik yoga aktif, atau Hatha, adalah sistem untuk mengembangkan kesejahteraan fisik dan mental melalui peregangan semua kelompok otot untuk kekuatan, kelenturan, dan keseimbangan fisik. Yoga sebagai terapi pelengkap dianggap lebih terapeutik daripada olahraga tradisional karena melibatkan keterlibatan aktif antara pikiran dan tubuh. Praktiknya telah dikaitkan dengan peningkatan kekuatan otot, daya tahan, kelenturan, rentang gerak, dan daya tahan kardiopulmoner. Yoga terutama bekerja pada peningkatan kesadaran tubuh dan proprioception, yang akan mengarah pada peningkatan keseimbangan pada orang dewasa yang lebih tua (Patel dkk., 2019).

Yoga terkenal dapat meningkatkan keseimbangan dan faktor psikologis lainnya. yoga aman untuk digunakan pada populasi umum. Peneliti yoga dapat mempertimbangkan untuk mengevaluasi postur yang meningkatkan keseimbangan dan menggunakan ukuran yang lebih sensitif dalam penelitian yang dirancang dengan baik (Jeter dkk., 2014). Keseimbangan tubuh, yang bertujuan untuk menstabilkan tubuh melawan hukum gravitasi baik dalam posisi tegak maupun saat bergerak, merupakan fungsi penting bagi manusia. Latihan fisik telah umum 
digunakan untuk meningkatkan keseimbangan tubuh dengan menggunakan protokol individu yang menggunakan latihan ketahanan seperti pelatihan dinamis dan statis atau dengan menerapkan latihan yang memfasilitasi adaptasi (penyesuaian informasi sensorik karena kondisi operasi baru) atau habituasi (modulasi di inti vestibular ) untuk menyeimbangkan gangguan, sehingga mengurangi efeknya pada tubuh (Prado dkk., 2014).

Yoga telah terbukti meningkatkan kekuatan otot, kelenturan, dan keseimbangan. program YoMed untuk digunakan sebagai intervensi klinis pada individu yang lebih tua.(Wooten dkk., 2018). Program latihan berbasis yoga dapat meningkatkan mobilitas di antara orang-orang yang berusia di atas 60 tahun dan mungkin membantu mencegah jatuh dengan meningkatkan keseimbangan, menurut tinjauan baru dari penelitian yang ada. Secara keseluruhan, yoga dikaitkan dengan peningkatan kecil dalam keseimbangan dan peningkatan sedang dalam mobilitas - seperti kecepatan berjalan dan seberapa mudah seseorang dapat turun dari kursi meskipun penulis ulasan secara khusus tertarik pada efek pada keseimbangan. Untuk melatih keseimbangan, Anda perlu melakukan aktivitas yang menantang keseimbangan dan melakukan aktivitas ini dengan posisi berdiri (Kathryn Doyle, 2016).

Para profesional kesehatan dengan percaya diri dapat merekomendasikan yoga untuk mereka yang berusia 60+ untuk meningkatkan keseimbangan dan mobilitas fisik. Latihan berbasis yoga menunjukkan janji sebagai pencegah jatuh intervensi. Uji coba terkontrol acak yang dirancang dengan baik untuk menyelidiki efek yoga pada kejadian jatuh. Keseimbangan dan mobilitas dapat ditingkatkan dengan aman dengan partisipasi dalam yoga pada mobilitas dengan Latihan berbasis yoga meningkatkan keseimbangan dan mobilitas pada orang tua orang berusia 60 tahun ke atas. Yoga fisik memerlukan penyelidikan sebagai intervensi potensial untuk mencegah jatuh di usia tua (Youkhana dkk., 2016).

Tetap aktif sepanjang hidup sangat penting dalam menjaga kualitas hidup, terutama pada lansia. Menemukan cara berolahraga yang efektif, aman, dan memiliki banyak manfaat bisa jadi menakutkan. Yoga tampaknya memengaruhi beberapa area, dan efek positifnya dapat dinikmati setelah waktu yang relatif singkat. Praktisi pemula juga dapat merasakan hasil yang positif. Sebagian besar penelitian yoga telah membuahkan hasil positif terkait keseimbangan, kekuatan otot, fleksibilitas, dan perbaikan suasana hati, terutama rasa takut jatuh. Yang perlu diperhatikan adalah peningkatan keseimbangan statis tidak tergantung pada waktu dan durasi latihan yoga. Selain aspek fisik yang penting, beberapa penelitian menemukan peningkatan efektivitas juga dan menggunakan yoga dalam mengobati PTSD, kecemasan, juga depresi. Selain manfaat kesehatan keseluruhan dari berlatih yoga, keserbagunaannya juga penting. Ini dapat dipraktekkan di rumah atau dalam pengaturan yang terorganisir, sendiri atau dalam kelompok dan dapat disesuaikan dengan tingkat mobilitas, fleksibilitas atau pengalaman yang berbeda. Pada populasi lansia, di mana kemampuan beradaptasi sangat penting, yoga tampaknya memiliki keuntungan yang pasti (Boros dkk., 2018).

Yoga adalah praktik kuno; itu telah dikaitkan dengan aktivitas budaya, agama dan fisik selama lebih dari 2.000 tahun. Praktisi telah menegaskan pengaruhnya terhadap keseimbangan kesehatan emosional, fisik dan spiritual selama beberapa dekade, tetapi baru belakangan ini ada gerakan untuk mendukung klaim ini melalui penelitian. Sejauh ini, hasilnya sudah pasti, bukti signifikan tentang manfaat yoga yang luas, baik sebagai pengobatan maupun sebagai bentuk pencegahan dari pengobatan dan perawatan kesehatan (Rankin, 2015). Temuan penelitian menunjukkan bahwa latihan yoga selama 6 minggu secara signifikan mempengaruhi keseimbangan statis dan dinamis dengan mata terbuka dan tertutup, kelincahan, kekuatan otot ekstremitas atas dan bawah, kelenturan, ekstremitas atas dan bawah. Yoga (yoga Hatha) memiliki efek positif pada kebugaran fisik lansia. Efek ini termasuk meningkatkan kekuatan pada ekstremitas atas dan bawah, keseimbangan statis dan dinamis, dan kelincahan (Koohboomi dkk., 2015). 
Panti Sosial Tresna Werdha (PSTW) Sabai Nan Aluih Sicincin adalah panti terbesar di Sumatera Barat dengan jumlah lansia terbanyak. Jumlah lansia pada PSTW Sabai Nan Aluih adalah 110 orang yang dibagi menjadi 14 wisma. Usia lansia pada PSTW ini berkisar dari 61 -101 tahun. Hasil penelitian bahwa dalam sebuah survei analisis resiko jatuh pada lansia di PSTW tersebut hampir 96\% lansia beresiko untuk jatuh. Lansia memiliki riwayat pernah jatuh, memiliki fungsi penglihatan yang memburuk dan keterbatasan kemampuan fungsi mobilisasi fisik. Lansia juga memiliki faktor resiko untuk jatuh yang mana minimnya terdapat alat bantu keamanan mobilisasi di fasilitas publik yang ada di panti. Kondisi penyakit kronis yang dimiliki lansia juga memperburuk kemungkinan terjadinya jatuh pada lansia.

Lansia PSTW membutuhkan strategi khusus yang dapat memberikan kemungkinan kegiatan yang beragam, tidak memberatkan dan dapat dilakukan secara berkelompok kecil di dalam wisma. Aktivitas yang monoton dan kegiatan pencegahan jatuh yang minim memberikan lansia sebagai kelompok yang harus diperhtaikan kebutuhan nya secara sensitif. Yoga ringan merupakan kegiatan yang mudah dan sederhana untuk dapat memberikan peningkatan terhadap kekuatan fisik mobilitas lansia sehingga mmeungkinkan berkurangnya resiko untuk jatuh.

Sebagian besar pengasuh di panti tersebut mempunyai latar belakang pendidikan umum (non Kesehatan) dari 30 karyawan yang ada hanya memeliki satu orang tenaga kesehatan. Setelah dilakukan studi kelapangan sebagian besar lansia tidak mengerti tentang penyakit degenerative dan ganguan keseimbangan, sehingga lansia tersebut mempunyai resiko jatuh dan cidera, bila hal ini terjadi tentu akan berkurangnya kualitas hidup lansia dan akan menjadi beban bagi petugas yang mengasuh lansia di panti tersebut. Tujuan pengabdian masyarakat ini untuk memberikan pendidikan kesehatan tentang perubahan perubahan yang terjadi pada lansia yang mengakibatkan munculnya permasalahan gangguan keseimbangan pada lansia dan mengadakan pelatihan untuk pengasuh lansia dengan topik gangguan keseimbangan dan melatih pengasuh untuk melakukan latihan Yoga.

\section{METODE}

Kegiatan IBM ini adalah untuk membantu mitra dalam hal meningkatkan pengetahuan dan wawasan peserta tentang gangguan keseimbangan pada lansia dengan melakukan latihan keseimbangan dengan Yoga. Kegiatan pelatihan ini bertujuan agar lansia mampu mengidentifikasi perubahan yang terjadi di dalam diri dan mampu melakukan pencegahan terkait perubahan sehingga kualitas hidup lansia menjadi baik dan tidak menjadi beban bagi pengasuh. Kegiatan IBM ini ditawarkan dalam IBM berdasarkan survey awal kondisi penghuni Panti Sosial Tresna Werdha berdasarkan laporan praktik profesi peminatan mahasiswa gerontik di Panti Sosial Tresna Werdha didapatkan $15 \%$ lansia mengalami rematik, 30\% lansia mengalami inkontinesia urin, 20\% lansia jatuh dalam enam bulan terakhir.

Keterampilan yang dimiliki mitra pada saat ini masih bersifat individual artinya dari anggota kelompok yang akan dibina hanya beberapa orang saja memiliki keterampilan yang baik tentang merawat lansia, terhadap kondisi fisik, dan belum memiliki kemampuan terhadap permasalahan psikologis pada lansia, namun hal yang positif yang bisa kita kembangkan adalah mereka sangat ingin mempelajari dan mau mengembangkan diri agar mempunyai derajat kesehatan yang baik agar tidak menjadi beban bagi anggota keluarga. Selama ini mitra hanya menggunakan fasilitas pelayanan kesehatan, posyandu, puskesmas sebagai tempat berobat, dan mereka tidak mampu melakukan perawatan secara mandiri untuk pencegahan efek penyakit degeneratif pada diri sendiri dengan mengikuti penyuluhan, pelatihan keseimbangan dan selalu melakukan kegiatan secara mandiri dirumahnya. Nantinya diharapkan lansia yang ada di Panti Sosial Tresna Werdha 
dapat mengetahui latihan keseimbangan untuk menurunkan risiko jatuh pada lansia.

Untuk itu keinginan sungguh-sungguh dari mitra untuk memanfaatkan momen pelatihan ini menjadi perhatian tim kami untuk melanjutkan kegiatan praktek peminatan profesi mahasiswa keperawatan menjadi kegiatan pengabdian IBM pada lansia. Untuk mencapai tujuan peningkatan pengetahuan wawasan ketrampilan lansia di panti sosial Tresna Werdha adalah dengan metode ceramah, penyuluhan diskusi pelatihan keseimbangan dengan Yoga dan sebagainya.

a. Metode, ceramah, penyuluhan dan diskusi

Metode ceramah penyuluhan dan diskusi bertujuan memberikan pengertian dan pemahaman kepada mitra tentang apa itu proses menua dampak secara fisik dan psikologis permasalahan permasalahan tentang risiko jatuh. Bagaimana cara mengatasinya melalui pencegahan dengan menggunakan metode ceramah ini kita akan mengusahakan pertemuan mitra dengan tim pengabdian kepada masyarakat sebanyak tiga kali.

\section{b. Metode pelatihan dan demonstrasi}

Metode pelatihan dilaksanakan setelah selesai dilakukan metode ceramah, penyuluhan dan diskusi, metode ini bertujuan member pelatihan bagaimana cara melakukan: latihan keseimbangan dengan Yoga. Metode yang diterapkan disini disebut metode demonstrasi dan pelatihan, metode demonstrasi diterapkan pada tiga sesi pada masing masing permasalahan, setelah itu diadakan metode re-demontrasi dimana lansia diharapkan sudah mampu melakukan latihan keseimbangan dengan Yoga secara mandiri, setelah itu untuk evaluasi selama dua bulan kita membuatkan catatan oleh lansia setiap hari Untuk ke tiga keterampilan lansia akan dibina sebanyak 25 orang di Panti Sosial Tresna Werdha, diharapkan, setelah mempelajari semua pelatihan keterampilan keseimbangan ini baik teori maupun praktek, mitra dapat melakukan setiap hari yang dipastikan akan dapat meningkatan derajat kesehatan lansia.

\section{HASIL DAN PEMBAHASAN}

Gambaran lokasi kegiatan pengabdian masyarakat dilaksanakan di Panti Sosial Tresna Werdha (PSTW) Sabai Nan Aluih Sicincin, adalah Unit Pelaksana Teknis Daerah (UPTD) Dinas Sosial Provinsi Sumatera Barat berdiri sejak tahun anggaran 1977/1978, melalui proyek pembinaan kesejahteraan lanjut usia. Direalisasikan suatu Unit Pelaksanaan Teknis di bidang Bina Kesejahteraan Sosial dan lingkungan Kantor Wilayah Departemen Sosial Provinsi Sumatera Barat. Departemen Sosial dilikuidasi, maka Panti Sosial Tresna Werdha (PSTW) Sabai Nan Aluih Sicincin menjadi UPTD di bawah Dinas Kesehatan dan Kesejahteraan Sosial Provinsi Sumatera Barat dengan keputusan Gubernur Sumatera Barat Nomor 22 tahun 2001, tanggal 01 November 2001. Kemudian seiring dengan berdirinya Dinas Sosial secara utuh, maka Panti Sosial Tresna Werdha (PSTW) Sabai Nan Aluih berada di bawahnya, dengan keputusan Gubernur Provinsi Sumatera Barat Nomor 32 tahun 2003.

Panti Sosial Tresna Werdha (PSTW) Sabai Nan Aluih Sicincin menyelenggarakan pelayanan terhadap lanjut usia terlantar dalam panti dengan kapasitas tampung sebanyak 110 orang. Sejak tahun 2008 sampai saat ini Panti Sosial Tresna Werdha (PSTW) Sabai Nan Aluih Sicincin menyelenggarakan pelayanan terhadap lanjut usia terlantar diluar panti atas partisipasi masyarakat khususnya melalui Lembaga Kesejahteraan Sosial (LKS) Lanjut Usia sebanyak 135 orang dalam penyelenggaraan kesejahteraan sosial kepada lanjut usia. Penyelenggaraan Kesejahteraan Sosial dan Lembaga Kesejahteraan Sosial (LKS) Lanjut Usia diwujudkan dalam berbagai kegiatan pelayanan yang telah dilaksanakan guna mewujudkan lanjut usia sehat dan bahagia (Zukhri, 2020). 
Pelaksanaan Pengabdian Masyarakat Panti Sosial Tresna Werdha (PSTW) Sabai Nan Aluih Sicincin pada tanggal 14-16 Agustus 2020. Edukasi tentang senam Yoga untuk keseimbangan lansia dilakukan kepada 30 penghuni Panti Sosial. Kegiatan pengabdian masyarakat dengan melibatkan mahasiswa tahap profesi ners stase gerontik yang sekaligus sebagai pelaksanaan kegiatan pembelajaran di tahap profesi. Tim dosen yang melakukan pengabdian masyarakat adalah Gusti Sumarsih Agoes, S.Kp, M.Biomed; Fitra Yeni, S.Kp,MA, dan Ns. Arif Rohman Mansur, M.Kep serta dibantu oleh sepuluh orang mahasiswa. Dosen Luar Biasa Fakultas keperawatan Unand yaitu Bapak Ns. Hastoro Dwinantoaji, PhD. Edukasi yang dilakukan dengan melakukan kunjungan ke beberapa wisma lansia yang bisa kooperatif, dengan tetap memperhatikan protokol kesehatan dan melakukan physical distancing, menggunakan APD seperti masker, dan FaceShield.

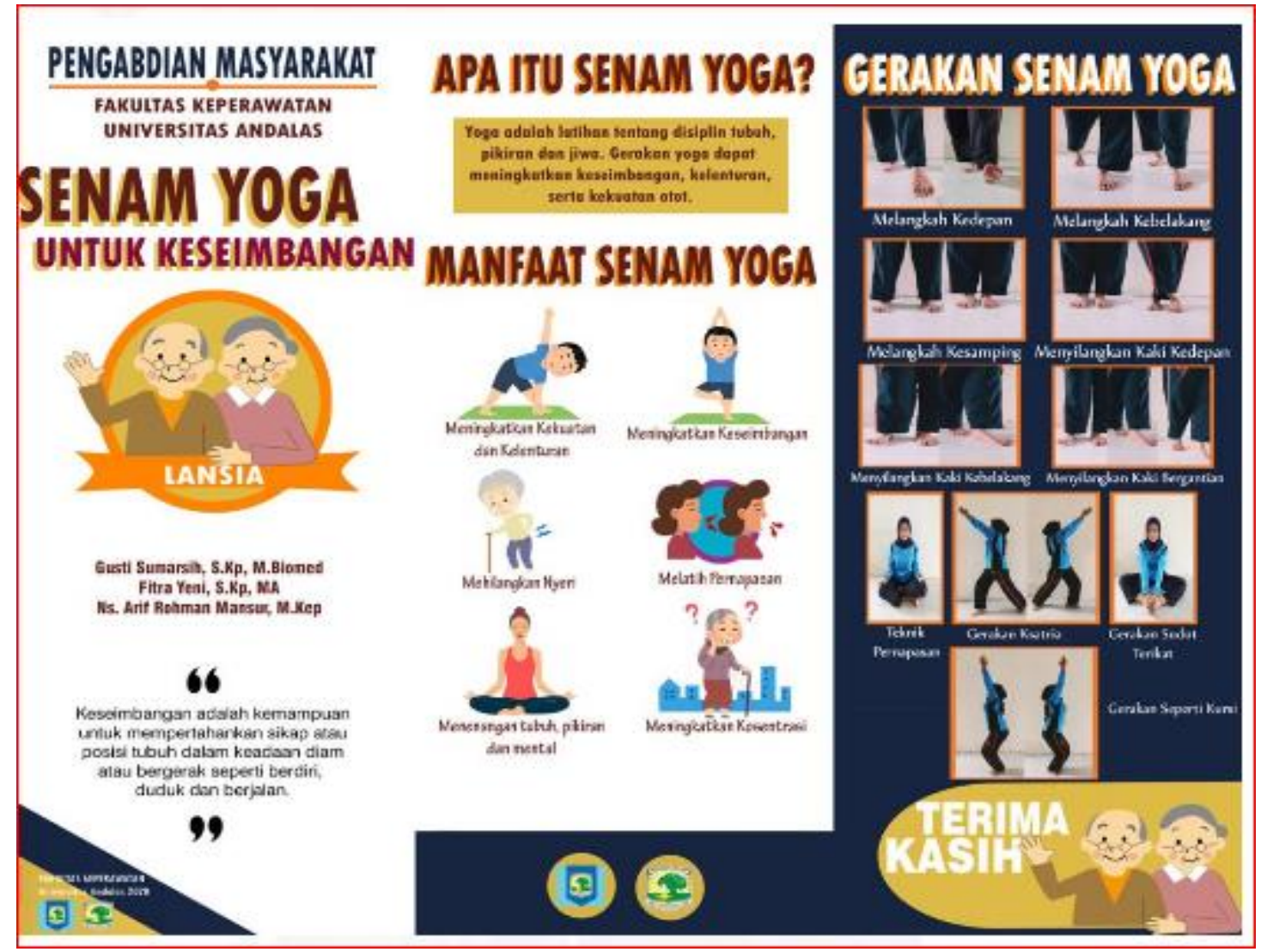

Gambar 1. Leaflet Edukasi yang Digunakan untuk Penyuluhan 


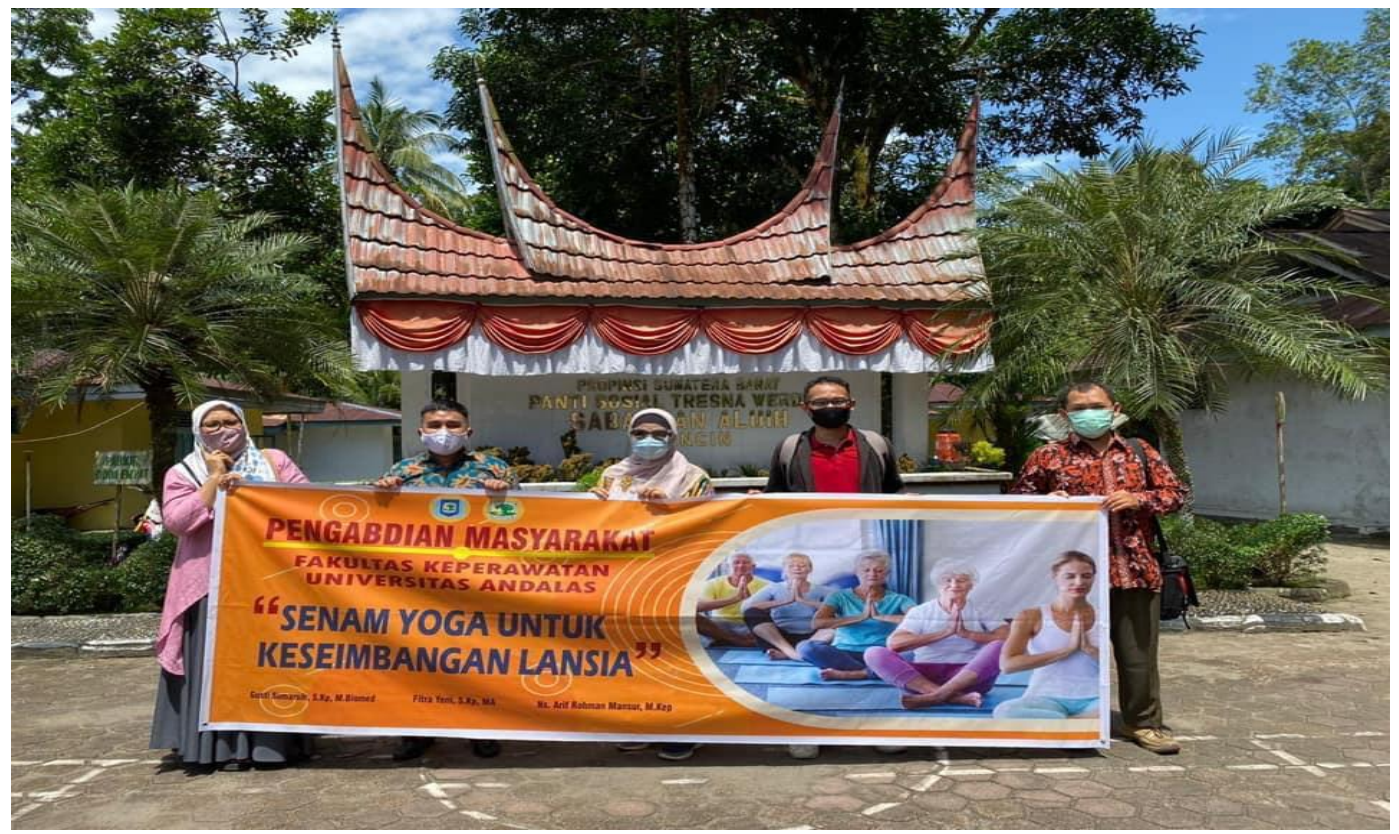

Gambar 2. Tim yang Melakukan Edukasi

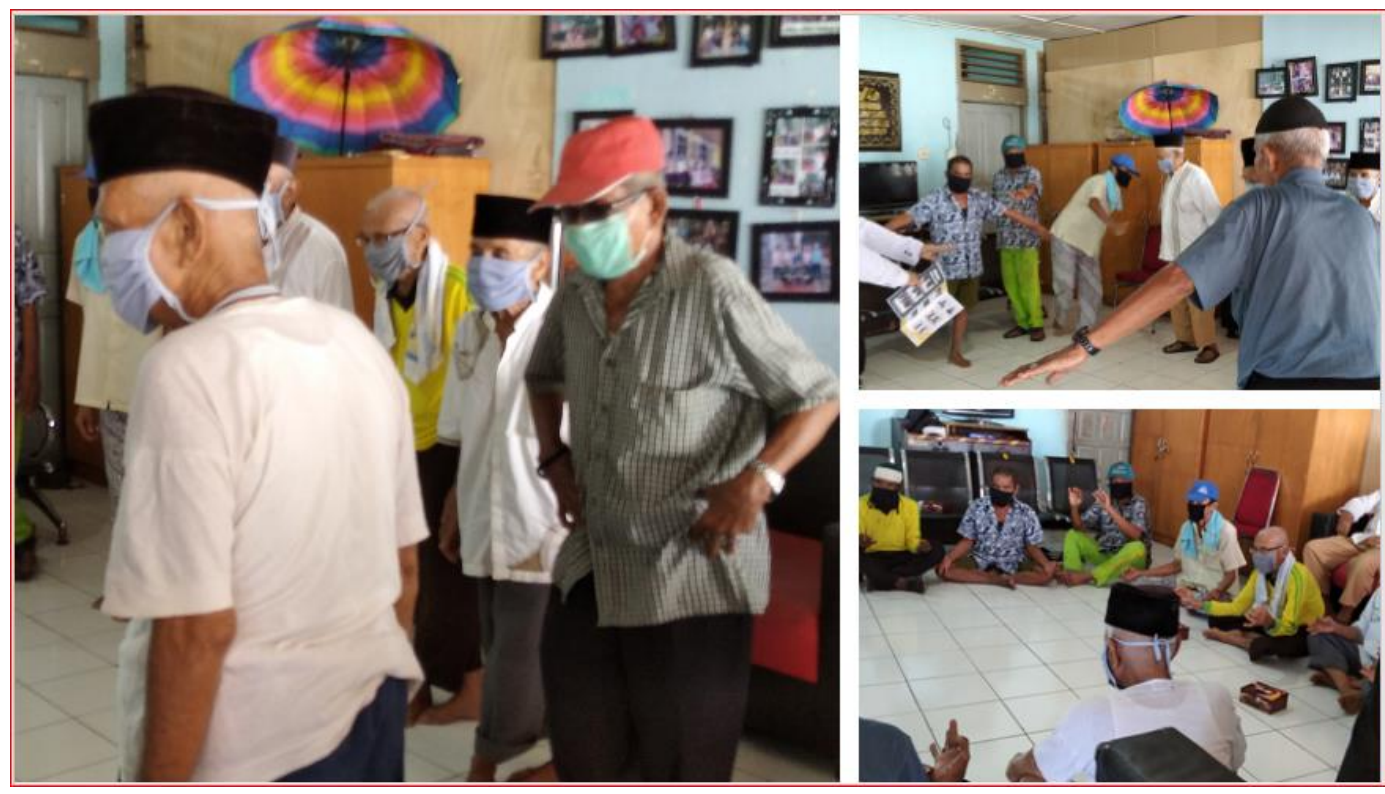

Gambar 3. Edukasi yang Dilakukan di Keluarga 


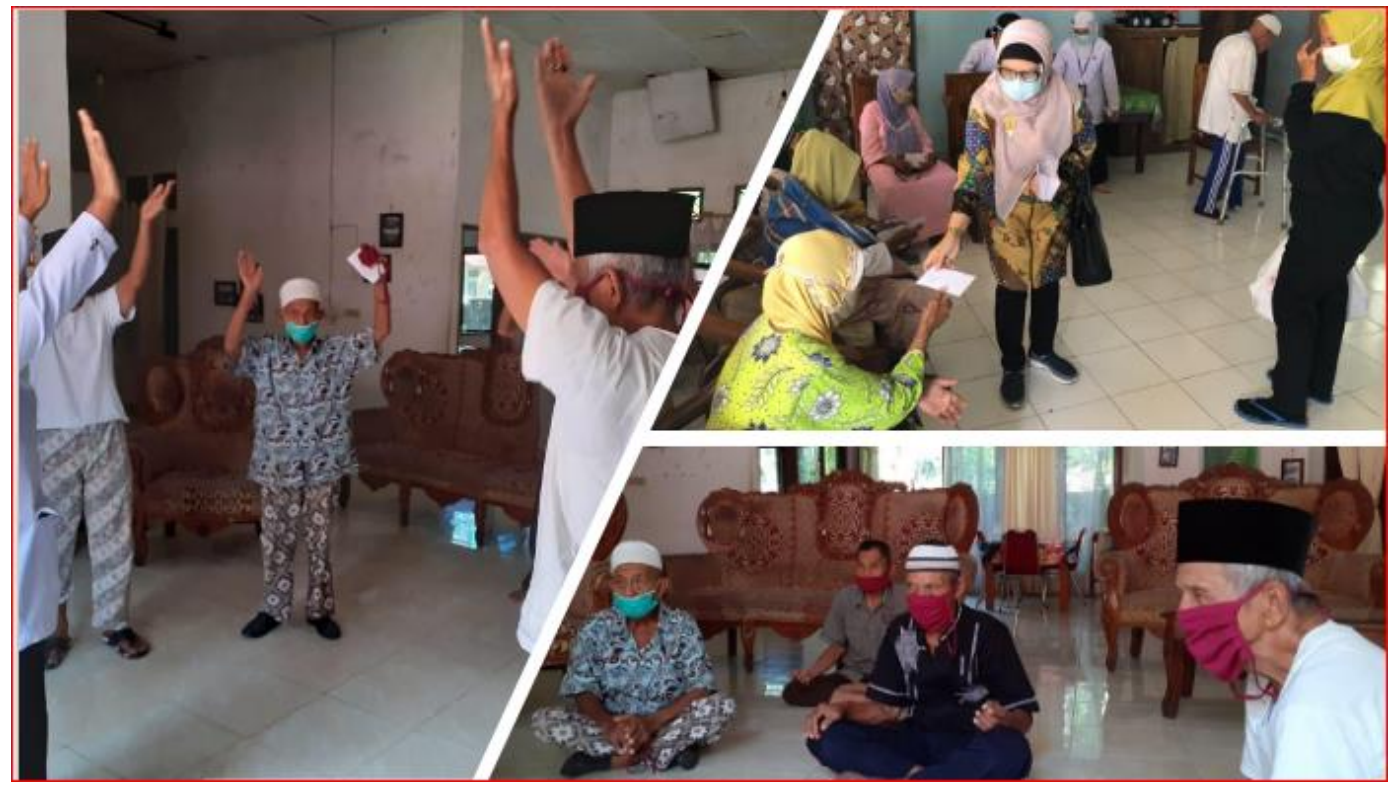

Gambar 4. Memberikan Bantuan Snack, Masker dan Uang Saku

\section{KESIMPULAN}

Kegiatan Pelatihan Keseimbangan dengan Penerapan Yoga pada Lansia dengan Risiko Jatuh di Panti Sosial Tresna Werdha Sabai Nan Aluih Sicincin berjalan dengan baik, diikuti oleh lansia dengan sangat antusias, semangat, mengikuti kegiatan ini dengan baik dari awal sampai akhir. Lansia juga diberikan edukasi untuk tetap melakukan latihan keseimbangan setelah kegiatan selesai dengan melihat tatacaranya pada leflet yang telah dibagikan. Selain itu lansia juga diberikan pengertian tentang manfaat melakukan kegiatan pelatihan keseimbangan tersebut, karena mereka mempunyai risiko tinggi untuk jatuh akibat berbagai faktor internal maupun eksternal. Pengabdi juga berkoordiansi dengan petugas panti akan mendorong lansia untuk melakukan latihan keseimbangan ini agar dapat meningkatkan keselamatan lansia dari risiko jatuh dan memperbaiki kualitas hidup lansia di Panti Sosial Tresna Werdha Sabai Nan Aluih Sicincin.

\section{UCAPAN TERIMA KASIH}

Terimakasih kepada UP2M Fakultas Keperawatan Universitas Andalas sebagai penyandang dana sehingga kegiatan Kegiatan Pelatihan Keseimbangan Dengan Penerapan Yoga Pada Lansia ini terlaksana dengan baik. Seluruh mahasiswa tahap profesi gerontic dan semua team dosen yang terlibat dalam kegiatan ini. Selanjutnya kepada dinas sosial provinsi Sumatera Barat yang telah memberikan ijin sehingga kegiatan ini terlaksana.

\section{DAFTAR PUSTAKA}

Badan Pusat Statistik. (2020). Statistik Penduduk Lanjut Usia 2020. https://www.bps.go.id/publication/2020/12/21/0fc023221965624a644c1111/statistikpenduduk-lanjut-usia-2020.html 
Boros, S., Csala, B., \& Szilágyi, E. (2018). Yoga Practice for The Elderly: Good Choice to Avoid Falls. Journal of Exercise, Sports \& Orthopedics, 5(1). https://symbiosisonlinepublishing.com/exercise-sports-orthopedics/exercise-sportsorthopedics66.php

Jeter, P. E., Nkodo, A.-F., Moonaz, S. H., \& Dagnelie, G. (2014). A Systematic Review of Yoga for Balance in a Healthy Population. Journal of Alternative and Complementary Medicine, 20(4), 221-232. https://doi.org/10.1089/acm.2013.0378

Kathryn Doyle. (2016). Yoga improves balance and mobility for older people / Reuters. https://www.reuters.com/article/us-health-yoga-balance-mobilityidUSKCNOUS2MY20160114

Koohboomi, M., Norasteh, A. A., \& Samami, N. (2015). Effect of Yoga Training on Physical Fitness and Balance in Elderly Females. Iranian Journal of Ageing, 10(3), 26-35.

National Institute on Aging. (2021). Understanding the Dynamics of the Aging Process. National Institute on Aging. http://www.nia.nih.gov/about/aging-strategic-directionsresearch/understanding-dynamics-aging

Patel, K. K., Deshmukh, M., \& Palekar, T. (2019). Effect of Yoga on Balance in Geriatric Population.

Prado, E. T., Raso, V., Scharlach, R. C., \& Kasse, C. A. (2014). Hatha yoga on body balance. International Journal of Yoga, 7(2), 133-137. https://doi.org/10.4103/0973-6131.133893

Rankin, D. (2015). The science of yoga-What research reveals. Elsevier Connect. https://www.elsevier.com/connect/the-science-of-yoga-what-new-research-reveals

Salzman, B. (2010). Gait and Balance Disorders in Older Adults. American Family Physician, 82(1), 61-68.

Svraka, E., Pecar, M., Jaganjac, A., Hadziomerovic, A. M., Kaljic, E., \& Kovacevic, A. (2017). Physical Therapy in Elderly Suffering from Degenerative Diseases. Materia Socio-Medica, 29(4), 272275. https://doi.org/10.5455/msm.2017.29.272-275

Thomas, E., Battaglia, G., Patti, A., Brusa, J., Leonardi, V., Palma, A., \& Bellafiore, M. (2019). Physical activity programs for balance and fall prevention in elderly: A systematic review. Medicine, 98(27).

Wooten, S. V., Signorile, J. F., Desai, S. S., Paine, A. K., \& Mooney, K. (2018). Yoga meditation (YoMed) and its effect on proprioception and balance function in elders who have fallen: A randomized control study. Complementary Therapies in Medicine, 36, 129-136. https://doi.org/10.1016/j.ctim.2017.12.010

Youkhana, S., Dean, C. M., Wolff, M., Sherrington, C., \& Tiedemann, A. (2016). Yoga-based exercise improves balance and mobility in people aged 60 and over: A systematic review and metaanalysis. Age and Ageing, 45(1), 21-29. https://doi.org/10.1093/ageing/afv175 
Zukhri. (2020). PELAYANAN DAN PERLINDUNGAN LANJUT USIADALAM PANTI SOSIAL TRESNA WERDHA (PSTW)SABAI NAN ALUIH SICINCINKABUPATEN PADANG PARIAMAN. https://webcache.googleusercontent.com/search?q=cache:bsQONPMKvcJ:https://sumbarprov.go.id/images/1469984549-

5.\%2520zuhri.pdf $+\& c d=2 \& h l=e n \& c t=c \ln \& \& g=i d$ 